\title{
Produção de ácido lático por Lactobacillus curvatus em melaço de cana-de-açúcar
}

\section{Lactic acid production by $L$. curvatus in sugarcane molasses}

\author{
Maria Celia de Oliveira Hauly ${ }^{1 *}$; Andréa Rocha de Oliveira ${ }^{2}$; Antonio Sérgio de Oliveira ${ }^{1}$
}

\section{Resumo}

A maior parte da produção mundial de ácido lático é utilizada pela indústria de alimentos e o restante em indústrias farmacêutica, têxtil, de couro, cosmética e química. A Metodologia da Superfície de Resposta, planejamento fatorial incompleto $3^{3}$, foi utilizada para estabelecer as melhores condições, relativas às concentrações, do meio de cultivo contendo melaço de cana-de-açúcar, extrato de levedura e peptona para desenvolvimento da fermentação descontínua por Lactobacillus curvatus. A fermentação se desenvolveu durante 48 horas sob temperatura de $37^{\circ} \mathrm{C}$. O modelo matemático fornecido pela Metodologia da Superfície de Resposta apontou os valores máximos de concentração testados para melaço de canade-açúcar, $10 \%(\mathrm{~m} / \mathrm{v})$; extrato de levedura, $2 \%(\mathrm{~m} / \mathrm{v})$ e peptona, $4 \%(\mathrm{~m} / \mathrm{v})$ como a melhor composição do meio para produção de ácido lático. Na prática, estas condições forneceram uma produção de 30,5g/L de ácido láctico, sendo este resultado comparável ao obtido em meio sintético de Man-Rogosa-Sharpe, o qual produziu $32,0 \mathrm{~g} / \mathrm{L}$ de ácido lático. Considerando-se o baixo custo e alta disponibilidade do melaço, pode-se afirmar que este representa um bom meio de cultivo para a fermentação lática. Fermentação descontínua em escala maior, fermentador de 3L, utilizando-se melaço de cana-de-açúcar $10 \%(\mathrm{~m} / \mathrm{v})$ suplementado com $2 \%$ (m/v) de extrato de levedura e $4 \%(\mathrm{~m} / \mathrm{v})$ de peptona produziu $37,5 \mathrm{~g} / \mathrm{L}$ de ácido lático.

Palavras-chave: Lactobacillus curvatus, fermentação descontínua, melaço de cana-de-açúcar, suplementação, ácido lático.

\begin{abstract}
Lactic acid is important due to its various applications. The bulk of world lactic acid production is used by the food industry and the rest is used in pharmaceutical, textile, leather, cosmetic and chemical industries. In this work, a $3^{3}$ incomplete factorial design of the response-surface methodology was used to determine the best concentration of sugarcane molasses, yeast extract and peptone in the culture medium for the development of batch lactic fermentation by Lactobacillus curvatus. The fermentation was carried out at $37^{\circ} \mathrm{C}$ for 48 hours without agitation. The mathematical model given by the responsesurface methodology indicated a concentration of $10 \%(\mathrm{w} / \mathrm{v})$ of sugarcane molasses, $2 \%(\mathrm{w} / \mathrm{v})$ of yeast extract and $4 \%(\mathrm{w} / \mathrm{v})$ of peptone as the best conditions for the composition of culture medium for the lactic acid production by L. curvatus. Under these conditions, lactic acid production was $30,5 \mathrm{~g} / \mathrm{L}$, comparable with the result obtained in MRS medium, which produced 32,0g/L of lactic acid. Considering the low cost and high availability of the sugarcane molasses, it was concluded that it represented a good culture medium for lactic fermentation. Sugarcane molasses at $10 \%(\mathrm{w} / \mathrm{v})$ supplemented with yeast extract at $2 \%(\mathrm{w} / \mathrm{v})$ and peptone at $4 \%(\mathrm{w} / \mathrm{v})$ was used in the $3 \mathrm{~L}$ batch lactic fermentation producing $37,5 \mathrm{~g} / \mathrm{L}$ of lactic acid.
\end{abstract}

Key words: Lactobacillus curvatus, batch fermentation, sugarcane molasses, supplementation, lactic acid.

1 Docentes do Departamento de Bioquímica/CCE/UEL - Caixa Postal 6001, 86051-970, Londrina - PR. Email: moch@uel.br

2 Aluna do Curso de Mestrado em Ciência e Tecnologia de Alimentos e Medicamentos/CCA/TAM/UEL

* Autor para correspondência. 


\section{Introdução}

O ácido lático, ácido 2-hidroxipropiônico ou ácido $\alpha$-hidroxipropiônico, tornou-se comercialmente importante desde 1881 (BARUFFALDI, 1975) tendo aplicação nas indústrias alimentícia, farmacêutica, cosmética, têxtil, de couro e química. Na indústria química é empregado como matéria-prima para produção de plásticos biodegradáveis (DEMIRCI et al., 1998; EVANGELISTA; NIKOLOV, 1996; JAGNOW; DAWID, 1991; MONTELONGO; CHASSY; McCORD, 1993). A maior aplicação do ácido lático e seus derivados é efetuada na indústria de alimentos, onde é utilizado com as funções de diminuição de $\mathrm{pH}$; como agente antimicrobiano; adjuvante de sabor; solvente; estabilizador; umectante; emulsificador; plasticizante, além de ser reconhecido como seguro pela "Food and Drug Administration" (FDA) (LITCHFIELD, 1996).

O ácido lático pode ser obtido tanto pela ação fermentativa de bactérias, fungos e leveduras quanto por síntese química. Porém, os processos fermentativos são mais vantajosos por serem mais econômicos (SILVA; MANCILHA, 1991). De acordo com Siebold et al. (1995) a produção de ácido lático em escala comercial ainda é feita, em sua maioria, pela fermentação descontínua. As bactérias láticas são bastante exigentes quanto às condições de crescimento. Segundo Buchta (1983) os açúcares representam as melhores fontes de carbono para estas bactérias, havendo também necessidade de fonte de nitrogênio, vitaminas e sais minerais para o bom desempenho da fermentação lática.

Diversos subprodutos e matérias-primas da indústria de alimentos e/ou da agroindústria têm sido empregados para o crescimento de microrganismos, pela alta disponibilidade e baixo custo. Exemplificando-se, o soro de leite, água de maceração de milho, xarope de milho, levedura de destilaria e melaços (MORAES; CAPALBO; MORAES, 1991). Dentre estes, os melaços destacam-se como meio de cultivo nos processos fermentativos, em virtude do alto teor de açúcares, nitrogênio e vitaminas.
Cerca de 17,9 milhões de toneladas de melaço de cana-de-açúcar são produzidos por ano no Brasil durante a fabricação do açúcar. Devido sua composição rica em açúcares fermentescíveis (LIMA; AQUARONE; BORZANI, 1975), seu baixo custo $(\mathrm{R} \$ 0,15 / \mathrm{Kg})$ e alta disponibilidade no território brasileiro, o melaço de cana-de-açúcar é sugerido como substrato para melhorar e reduzir custos na produção de ácido lático pelo L. curvatus.

O objetivo deste trabalho foi determinar a melhor composição do meio de cultivo para a produção de ácido lático pelo L. curvatus por fermentação descontínua, através da Metodologia da Superfície de Resposta, utilizando como meio de cultivo melaço de cana-de-açúcar enriquecido com extrato de levedura e peptona.

\section{Material e Métodos}

\section{Material}

Microrganismo: foi utilizado Lactobacillus curvatus isolado de silagem de milho por Oliveira (1995).

\section{Meios de cultivo}

Meio de manutenção: L. curvatus foi mantido em tubos contendo ágar MRS (Man-Rogosa-Sharpe). As culturas foram repicadas a cada 4 semanas e incubadas durante 24 horas à $37^{\circ} \mathrm{C}$. A seguir foram mantidas em câmara fria à $4{ }^{\circ} \mathrm{C}$.

\section{Meios para fermentação}

\section{- Caldo MRS (Man-Rogosa-Sharpe)}

- Melaço de cana-de-açúcar, previamente tratado com invertase, e suplementado com extrato de levedura e peptona, de acordo com o delineamento estatístico da Metodologia da Superfície de Resposta, indicado na Tabela 1. O melaço de canade-açúcar foi adquirido da Usina de Açúcar e Álcool da COROL (Cooperativa Agropecuária Rolândia Ltda)-PR. 
A enzima invertase foi extraída de levedura de panificação, segundo Nepomuceno (1998).

\section{Métodos}

Preparo do meio de cultivo de melaço de canade-açúcar

O melaço de cana-de-açúcar foi diluído em água destilada para obtenção das concentrações de 2; 6 e $10 \%(\mathrm{~m} / \mathrm{v})$, correspondentes aos níveis reais da variável $\mathrm{X}_{1}$ no delineamento estatístico indicados na Tabela 1. Em seguida, o pH do meio de melaço de cana-de-açúcar foi ajustado para o valor de 4,7 para e incubação com invertase por 20 minutos a $37^{\circ} \mathrm{C}$. A enzima com atividade de $13.48 \mathrm{U} / \mathrm{mL}$ foi utilizada na concentração de $2 \%$ (v/v). Após incubação, a invertase foi inativada através de fervura durante 5 minutos. $\mathrm{O}$ pH do meio foi ajustado para o valor 6,2.

Tabela 1. Delineamento estatístico para o desenvolvimento da fermentação lática pelo Lactobacillus curvatus por processo descontínuo.

\begin{tabular}{cccc}
\hline \multirow{2}{*}{ Tratamentos } & \multicolumn{3}{c}{ Variáveis codificadas } \\
\cline { 2 - 4 } & $\mathrm{X}_{1}$ & $\mathrm{X}_{2}$ & $\mathrm{X}_{3}$ \\
\hline 1 & -1 & -1 & 0 \\
2 & 1 & -1 & 0 \\
3 & -1 & 1 & 0 \\
4 & 1 & 1 & 0 \\
5 & -1 & 0 & 1 \\
6 & 1 & 0 & -1 \\
7 & -1 & 0 & 1 \\
8 & 1 & 0 & 1 \\
9 & 0 & -1 & -1 \\
10 & 0 & 1 & -1 \\
11 & 0 & -1 & 1 \\
12 & 0 & 1 & 1 \\
13 & 0 & 0 & 0 \\
14 & 0 & 0 & 0 \\
15 & 0 & 0 & 0 \\
\hline $\mathrm{X}_{1}$, melaço de cana-de-açúcar ${ }^{\mathrm{a}}$ & $2 \%$ & $6 \%$ & $10 \%$ \\
$\mathrm{X}_{3}$, peptona de levedura & $0 \%$ & $1 \%$ & $2 \%$ \\
\hline & $0 \%$ & $2 \%$ & $4 \%$ \\
\hline & \multicolumn{3}{c}{0} \\
\hline
\end{tabular}

${ }^{a}$ melaço de cana-de-açúcar tratado previamente com invertase.

\section{Fermentação lática}

Preparo do inóculo: para preparo do inóculo o $L$. curvatus foi inicialmente ativado através de 3 recipientes sucessivos em leite em pó desengordurado e na concentração de $10 \%(\mathrm{~m} / \mathrm{v})$. A cada repique, o cultivo foi mantido a $37^{\circ} \mathrm{C}$ durante 24 horas. O inóculo foi preparado cultivando-se o $L$. curvatus no meio de fermentação durante 24 horas a $37^{\circ} \mathrm{C}$ e utilizado na concentração de $10 \%$ (v/v) para as fermentações.

Fermentação descontínua: o processo descontínuo foi desenvolvido utilizando-se como meio de cultivo o melaço de cana-de-açúcar, previamente tratado com invertase, e suplementado com extrato de levedura e peptona, conforme delineamento estatístico indicado na Tabela 1. Os diferentes tratamentos, quanto à composição do meio de cultivo, indicados na Tabela 1, foram desenvolvidos em frascos erlenmeyers de $125 \mathrm{~mL}$ contendo $20 \mathrm{~mL}$ do respectivo meio de cultivo. $\mathrm{O}$ pH inicial do meio foi de 6,2 e a fermentação foi desenvolvida durante 48 horas sob temperatura de $37^{\circ} \mathrm{C}$. Após definição da melhor composição do meio de cultivo para produção de ácido lático, em frascos erlenmeyers de $125 \mathrm{~mL}$, esta foi utilizada na fermentação descontínua em escala maior, utilizando-se fermentador de $3 \mathrm{~L}$. O pH inicial do meio de cultivo foi de 6,2. A fermentação foi desenvolvida durante 48 horas sob temperatura de $37^{\circ} \mathrm{C}$ e agitação de 150 r.p.m. para homogeneização do meio.

\section{Determinações analíticas}

Amostras do caldo fermentado foram utilizadas para determinação de $\mathrm{pH}$ com potenciômetro HI 9321-Hanna Instruments. Após centrifugação a 2000xg por 10 minutos, reservou-se o sobrenadante para determinações de ácido lático pelo método do cloreto férrico (SILVA, 1981) e determinação de açúcares redutores pelo método de Somogyi (1945) e Nelson (1944). A biomassa foi determinada pela leitura da densidade óptica em espectrofotômetro UV/VIS - Metrolab a $600 \mathrm{~nm}$ (GOUVEIA, 1995). 
A viabilidade celular foi avaliada através da técnica de semeadura em profundidade de acordo com Zayed e Winter (1995). As placas foram incubadas a $37^{\circ} \mathrm{C}$ por 48 horas.

\section{Análises estatisticas}

O delineamento fatorial incompleto, $3^{3}$, da Metodologia da Superfície de Resposta (BARROS; SCARMINIO; BRUNS, 1996) foi usado para investigar o efeito de três variáveis independentes: concentração de melaço de cana-de-açúcar $(\mathrm{m} / \mathrm{v})$, extrato de levedura $(\mathrm{m} / \mathrm{v})$ e peptona $(\mathrm{m} / \mathrm{v})$, com três níveis de variação (codificados com $-1,0$ e 1 ) na produção de ácido lático pelo L. curvatus em processo descontínuo desenvolvido em frascos erlenmeyers de $125 \mathrm{~mL}$, contendo $20 \mathrm{~mL}$ de meio de cultivo. $\mathrm{O}$ delineamento experimental constituiu-se de 15 ensaios, apresentados na Tabela 1.

\section{Resultados e Discussão}

O melaço de cana-de-açúcar apresentou em sua composição 17\% de água; 66 \% de açúcares, sendo $16 \%$ açúcares redutores (glicose e frutose) e 50\%, sacarose; $8 \%$ de cinzas, $4 \%$ de matéria nitrogenada e $5 \%$ de outros. Sendo assim, uma matéria-prima rica em açúcares fermentescíveis. Devido ao baixo custo e alta disponibilidade, o melaço de cana-deaçúcar vem sendo utilizado como meio de cultivo para fermentação (LITCHFIELD, 1996).

Considerando que Oliveira (1995) verificou que o L. curvatus possui baixo metabolismo de sacarose, e a sacarose é o açúcar presente em maior quantidade no melaço de cana-de-açúcar, investigouse previamente a hidrólise enzimática deste substrato a fim de disponibilizar açúcares prontamente fermentescíveis ao microrganismo. Os resultados revelaram que em melaço de cana-de-açúcar $10 \%$ $(\mathrm{m} / \mathrm{v})$, tratado previamente com invertase, o $L$. curvatus produziu $14,6 \mathrm{~g} / \mathrm{L}$ de ácido lático, enquanto que em melaço de cana-de-açúcar $10 \%$ (m/v), não tratado com invertase, a produção foi de $10 \mathrm{~g} / \mathrm{L}$. Martínez-González et al. (1988) obtiveram considerável quantidade de açúcares invertidos quando trataram o melaço de cana-de-açúcar com ácido sulfúrico e calor para melhorar a produção de ácido lático por L. delbrueckii. Entretanto, os processos biotecnológicos de hidrólise da sacarose bem como sacarificação do amido através de enzimas microbianas são economicamente mais viáveis, uma vez que estas atuam sobre seus substratos de forma livre ou imobilizadas em suportes sólidos (JAGNOW; DAWID, 1991) o que pode facilitar o processo industrial.

A Tabela 2 mostra o delineamento estatístico utilizado e a produção de ácido lático pelo L. curvatus nas diferentes condições. O melhor resultado experimental, 29,9g/L de ácido lático foi obtido no tratamento $\mathrm{n}^{\mathrm{o}} \cdot 4$, constituído de melaço de cana-deaçúcar a $10 \%(\mathrm{~m} / \mathrm{v})$; extrato de levedura $2 \%(\mathrm{~m} / \mathrm{v})$ e peptona $2 \%(\mathrm{~m} / \mathrm{v})$. A condição menos adequada para produção de ácido lático $(7,9 \mathrm{~g} / \mathrm{L})$ foi obtida no tratamento $\mathrm{n}^{\mathrm{o} .}$ 9, constituído somente de melaço de cana-de-açúcar $6 \%(\mathrm{~m} / \mathrm{v})$ sem suplementação com extrato de levedura ou peptona. A concentração de ácido lático obtida no meio composto por melaço de cana-de-açúcar $6 \%(\mathrm{~m} / \mathrm{v})$; porém enriquecido com extrato de levedura $2 \%(\mathrm{~m} / \mathrm{v})$ e peptona $4 \%(\mathrm{~m} / \mathrm{v})$, tratamento de $\mathrm{n}^{\mathrm{o} .} 12$, foi de $18,7 \mathrm{~g} / \mathrm{L}$, ou seja, valor maior que o dobro quando comparado ao ácido lático obtido no meio constituído somente de melaço de cana-de-açúcar, o que está de acordo com pesquisas realizadas utilizando-se outras espécies de Lactobacillus ( MARTÍNEZ-GONZÁLEZ et al., 1988 ; HO et al., 1997; ZAYED; ZAHRAN, 1991; HUJANEN; LINKO, 1996; MONTELONGO; CHASSY; McCORD, 1993; SELMER-OLSEN; SORHAUG, 1998; DEMIRCI et al., 1998). O extrato de levedura é uma excelente fonte de vitaminas do complexo B e é freqüentemente usado para fornecer esses fatores em meios de cultura bacteriológicos, sendo considerado indispensável para se obter rápidas taxas de crescimento e produção de ácido lático por bactérias láticas (SELMER-OLSEN; SORHAUG, 1998). 
Tabela 2. Produção de ácido lático pelo Lactobacillus curvatus por processo descontínuo em frascos erlenmeyers de $125 \mathrm{~mL}$ contendo $20 \mathrm{~mL}$ de meio.

\begin{tabular}{ccccc}
\hline & $\begin{array}{c}\text { melaço de } \\
\text { Tratamentos } \\
\text { cana-de-açúcar } \\
\left(\mathrm{X}_{1}\right)\end{array}$ & $\begin{array}{c}\text { extrato de levedura } \\
\left(\mathrm{X}_{2}\right)\end{array}$ & $\begin{array}{c}\text { peptona } \\
\left(\mathrm{X}_{3}\right)\end{array}$ & ácido lático \\
& & $(\%)$ & $(\%)$ & \\
\hline 1 & $(\%)$ & & & \\
2 & 10 & 0 & 2 & 10,8 \\
3 & 2 & 0 & 2 & 22,2 \\
4 & 10 & 2 & 2 & 11,7 \\
5 & 2 & 2 & 2 & 29,9 \\
6 & 10 & 1 & 4 & 10,8 \\
7 & 2 & 1 & 0 & 19,3 \\
8 & 10 & 1 & 4 & 10,1 \\
9 & 6 & 1 & 4 & 27,9 \\
10 & 6 & 0 & 0 & 07,9 \\
11 & 6 & 2 & 0 & 16,3 \\
12 & 6 & 0 & 4 & 15,4 \\
13 & 6 & 2 & 4 & 18,7 \\
14 & 6 & 1 & 2 & 15,9 \\
15 & 6 & 1 & 2 & 18,2 \\
& & 1 & 2 & 16,1 \\
\hline
\end{tabular}

A Tabela 3 mostra os coeficientes de regressão para as respostas polinomiais ajustadas para a produção de ácido lático pelo L. curvatus.

O intercepto do modelo foi significativo, ao nível de $0,0001 \%$, demonstrando que o ponto central, melaço de cana-de-açúcar $6 \%(\mathrm{~m} / \mathrm{v})$; extrato de levedura $1 \%(\mathrm{~m} /$ v) e peptona $2 \%(\mathrm{~m} / \mathrm{v})$, foi escolhido adequadamente.

Os efeitos lineares das variáveis $\left(\mathrm{X}_{1}, \mathrm{X}_{2}\right.$ e $\left.\mathrm{X}_{3}\right)$ tiveram influência significativa na produção de ácido lático, de acordo com os valores de $\mathrm{p}$, nível de significância (Tabela 3). A variável $X_{1}$ (concentração de melaço de cana-de-açúcar) apresentou maior significância $(\mathrm{p}=0,001 \%)$ demonstrando a relevância desta variável na obtenção de ácido lático nas condições estudadas.

Dentre os parâmetros de interação estimados (Tabela 3), a interação de $\mathrm{X}_{1} \operatorname{com} \mathrm{X}_{2}$ foi mais significativa $(\mathrm{p}=1,9 \%)$ sugerindo que o uso do melaço de cana-de-açúcar suplementado com extrato de levedura pode ser mais adequado para produção de ácido lático por L. curvatus do que a suplementação do melaço somente com peptona. Hujanen e Linko (1996) investigando a influência de algumas fontes de nitrogênio na produção de ácido lático pelo $L$. casei em meio sintético contendo glicose $100 \mathrm{~g} / \mathrm{L}$ verificaram uma produção de $100 \mathrm{~g} / \mathrm{L}$ e $60 \mathrm{~g} / \mathrm{L}$ em 48 horas de cultivo quando utilizaram extrato de levedura e peptona, respectivamente. O ácido produzido durante a fermentação foi neutralizado com carbonato de cálcio para evitar inibição pelo produto final.

Tabela 3. Coeficientes de regressão para as respostas polinomiais ajustadas para a produção de ácido lático pelo Lactobacillus curvatus por fermentação descontínua.

\begin{tabular}{ccccccc}
\hline Coeficientes & $\beta$ & $\begin{array}{c}\text { desvio padrão } \\
\text { de } \beta\end{array}$ & $\begin{array}{c}\text { Parâmetro } \\
\text { estimado B }\end{array}$ & $\begin{array}{c}\text { desvio padrão de } \\
\text { B }\end{array}$ & t (5) & p $>\mathrm{T}$ \\
\hline Intercepto & & & 1.673333 & 0.057612 & 29.04512 & 0.000001 \\
$\mathrm{X}_{1}$ & 0.866330 & 0.050338 & 0.725714 & 0.042167 & 17.21035 & 0.000012 \\
$\mathrm{X}_{2}$ & 0.302917 & 0.042116 & 0.253750 & 0.035280 & 7.19252 & 0.000809 \\
$\mathrm{X}_{3}$ & 0.307257 & 0.049492 & 0.261786 & 0.042167 & 6.20826 & 0.001584 \\
$\mathrm{X}_{1} \mathrm{X}_{2}$ & 0.143500 & 0.042116 & 0.170000 & 0.049893 & 3.40729 & 0.019099 \\
$\mathrm{X}_{1} \mathrm{X}_{3}$ & 0.125528 & 0.055448 & 0.153929 & 0.067993 & 2.26390 & 0.072995 \\
$\mathrm{X}_{2} \mathrm{X}_{3}$ & -0.107625 & 0.042116 & -0.127500 & 0.049893 & -2.55547 & 0.050926 \\
$\mathrm{X}_{1} \mathrm{X}_{1}$ & 0.156060 & 0.046348 & 0.191369 & 0.056835 & 3.36712 & 0.019952 \\
$\mathrm{X}_{2} \mathrm{X}_{2}$ & 0.000243 & 0.046348 & 0.000298 & 0.056835 & 0.00542 & 0.996024 \\
$\mathrm{X}_{3} \mathrm{X}_{3}$ & -0.176254 & 0.046348 & -0.216131 & 0.056835 & -3.80280 & 0.012592 \\
\hline
\end{tabular}


A Figura 1 mostra a produção de ácido lático, fixando-se a variável de menor significância $X_{3}$, peptona $4 \%(\mathrm{~m} / \mathrm{v})$, e variando-se as concentrações de $\mathrm{X}_{1}$ (melaço de cana-de-açúcar) e $\mathrm{X}_{2}$ (extrato de levedura). Aumentando-se as concentrações de melaço e extrato de levedura, obtém-se melhores resultados na produção de ácido láctico, porém, é importante lembrar que concentrações maiores do que as avaliadas neste trabalho interferem no processo fermentativo utilizado devido a problemas de solubilidade dos constituintes no meio de cultivo.

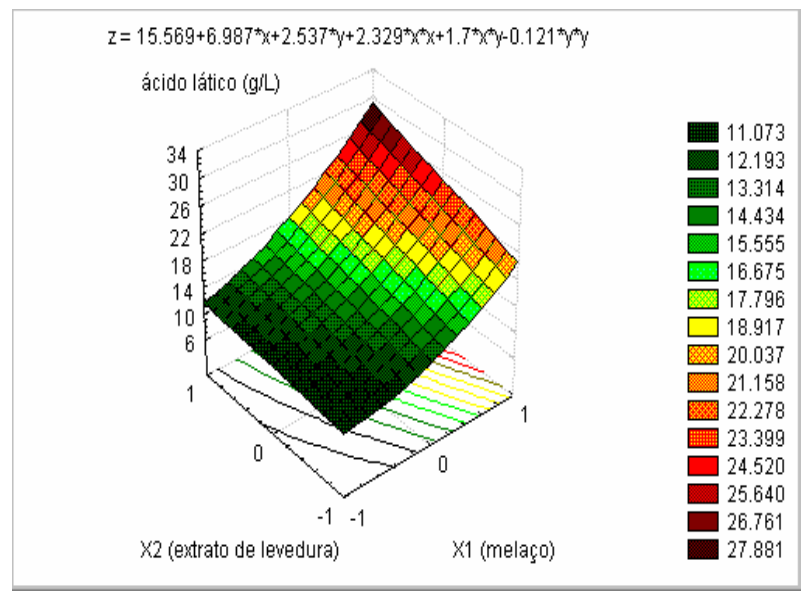

Figura 1. Produção de ácido lático pelo Lactobacillus curvatus em função da concentração de melaço de canade-açúcar $\left(\mathrm{X}_{1}\right)$ e concentração de extrato de levedura $\left(\mathrm{X}_{2}\right)$ em 48 horas de cultivo descontínuo.

A análise de variância dos resultados da fermentação lática descontínua desenvolvida pelo $L$. curvatus está indicada na Tabela 4.

Tabela 4. Análise de variância da fermentação lática descontínua, desenvolvida pelo Lactobacillus curvatus.

\begin{tabular}{cccccc}
\hline & $\begin{array}{c}\text { Graus de } \\
\text { liberdade }\end{array}$ & $\begin{array}{c}\text { Somas de } \\
\text { quadrados }\end{array}$ & $\begin{array}{c}\text { Quadrado } \\
\text { médio }\end{array}$ & $\mathrm{F}$ & $\mathrm{p}>\mathrm{F}$ \\
\hline Regressão & 9 & 5.563987 & 0.618221 & 62.08743 & 0.000135 \\
Residual & 5 & 0.049786 & 0.009957 & & \\
Total & & 5.613773 & & & \\
\hline
\end{tabular}

Para a resposta avaliada, ácido lático em $\mathrm{g} / \mathrm{L}$, observa-se que a regressão foi significativa ao nível de $0,0135 \%$. A porcentagem de variância explicada e porcentagem máxima de variância explicada pelo modelo foram de 97,5 e 99,1, respectivamente. Isto permite a utilização do modelo matemático, equação de regressão fornecida pela Metodologia da Superfície de Resposta

$$
\begin{aligned}
& Y=1,673333+0,725714 X_{1}+0,253750 X_{2}+ \\
& 0,261786 X_{3}+0,191369 X_{1}{ }^{2}+0,000298 X_{2}^{2}- \\
& 0,216131 X_{3}^{2}+0,17000 X_{1} X_{2}+0,153929 X_{1} X_{3}- \\
& 0,127500 X_{2} X_{3}
\end{aligned}
$$

onde:

$\mathrm{Y}=$ à ácido lático g/L;

$\mathrm{X}_{1}=$ à concentração de melaço de cana-de-açúcar $\%(\mathrm{~m} / \mathrm{v})$

$\mathrm{X}_{2}=$ à concentração de extrato de levedura \% (m/v);

$\mathrm{X}_{3}=$ à concentração de peptona $\%(\mathrm{~m} / \mathrm{v})$;

O modelo matemático fornecido pela Metodologia da Superfície de Resposta indicou que as melhores concentrações para produção de ácido lático pelo $L$. curvatus por processo descontínuo são valores máximos (codificados como $+1 ;+1 ;+1$ ) para melaço de cana-de-açúcar, $10 \%(\mathrm{~m} / \mathrm{v})$; extrato de levedura, $2 \%(\mathrm{~m} / \mathrm{v})$ e peptona, $4 \%(\mathrm{~m} / \mathrm{v})$ com uma produção de $30,9 \mathrm{~g} / \mathrm{L}$ de ácido lático. Na prática, a fermentação lática descontínua desenvolvida nestas condições produziu, em média, 30,5g/L de ácido láctico que é comparável à obtida em meio sintético, caldo MRS, cuja produção de ácido lático pelo L. curvatus foi de $32 \mathrm{~g} / \mathrm{L}$. O consumo de açúcares redutores pelo $L$. curvatus foi de 92,5\% tanto no meio de cultivo contendo melaço suplementado quanto em caldo MRS, utilizado como meio de referência para o L. curvatus.

As taxas de conversão de substrato observadas nestas condições foram de 0,87 e $0,86 \mathrm{~g} / \mathrm{g}$ para 
melaço de cana-de-açúcar suplementado e caldo MRS, respectivamente. Os valores de produtividade volumétrica obtidos em meio de melaço de cana-deaçúcar suplementado e em caldo MRS foram de 0,63 e $0,67 \mathrm{~g} / \mathrm{L} / \mathrm{h}$, respectivamente, demonstrando que $L$. curvatus nas melhores condições de fermentação apontadas pelo modelo matemático, fornecido pela Metodologia da Superfície de Resposta, apresenta boa produção de ácido lático quando comparado com o seu desempenho no meio sintético de MRS (Figura 2).
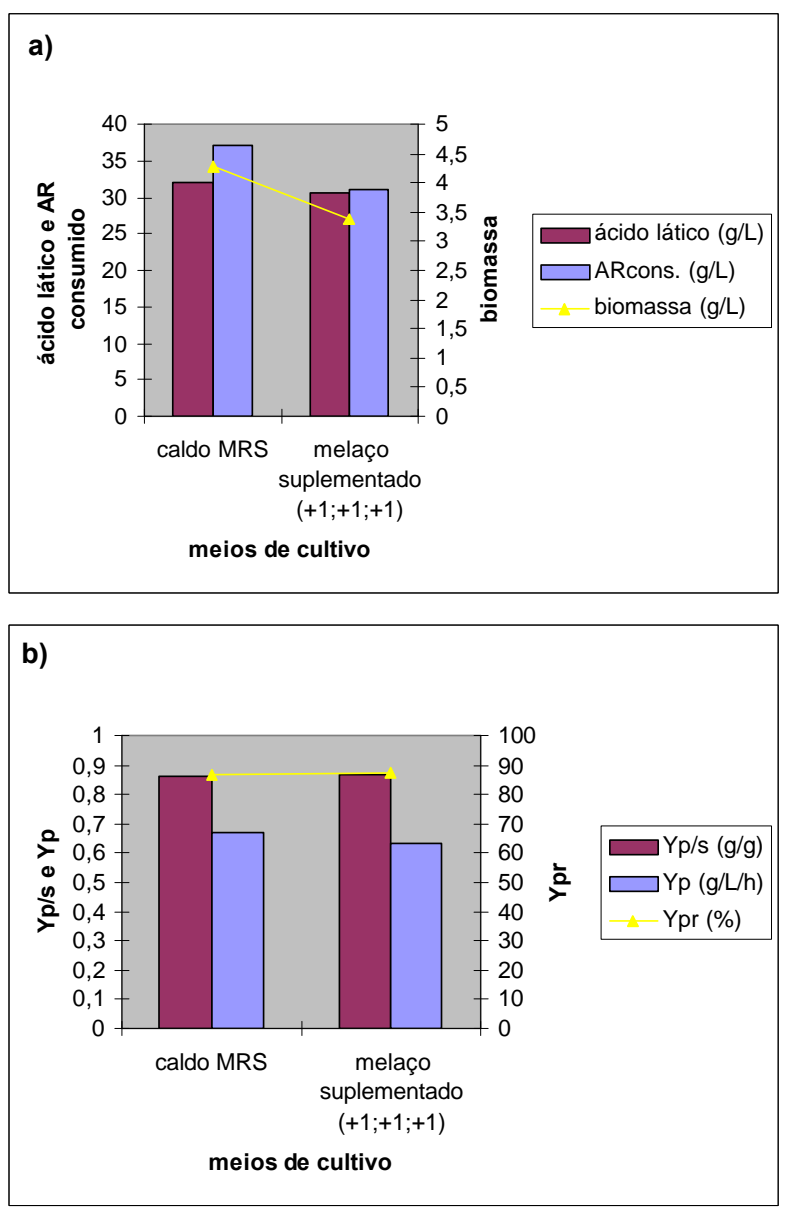

Figura 2. Fermentação lática descontínua desenvolvida pelo Lactobacillus curvatus em melaço de cana-de-açúcar suplementado e em caldo MRS: (a) produção de ácido lático, biomassa e consumo de açúcar; (b) parâmetros cinéticos avaliados: eficiência de conversão de substrato $\left(\mathrm{Y}_{\mathrm{p} / \mathrm{s}}\right)$, produtividade $\left(\mathrm{Y}_{\mathrm{pr}}\right)$ e produtividade volumétrica $\left(\mathrm{Y}_{\mathrm{p}}\right)$.
A melhor composição de meio de cultivo, indicada através da Metodologia da Superfície de Resposta, melaço de cana-de-açúcar $10 \%(\mathrm{~m} / \mathrm{v})$; extrato de levedura $2 \%(\mathrm{~m} / \mathrm{v})$ e peptona $4 \%(\mathrm{~m} / \mathrm{v})$ foi testada quanto à produção de ácido lático, por processo descontínuo em escala maior, fermentador de $3 \mathrm{~L}$. A fermentação foi desenvolvida durante 48 horas sob agitação de 150 r.p.m., sem controle de $\mathrm{pH}$, sendo o valor de $\mathrm{pH}$ inicial 6,2 , e temperatura de $37^{\circ} \mathrm{C}$. Os resultados são apresentados na Tabela 5.

Tabela 5. Fermentação lática descontínua desenvolvida pelo Lactobacillus curvatus, em fermentador de 3L,contendo meio de melaço de cana-de-açúcar $10 \%$ (m/ v) suplementado com extrato de levedura $2 \%(\mathrm{~m} / \mathrm{v})$ e peptona $4 \%(\mathrm{~m} / \mathrm{v})$.

\begin{tabular}{ccc}
\hline & \multicolumn{2}{c}{ horas de culivo } \\
\cline { 2 - 3 } & 24 & 48 \\
\hline $\mathrm{pH}$ final & 3,54 & 3,4 \\
Ác. lático (g/L) & 30,1 & 37,5 \\
$\mathrm{AR}_{\mathrm{c}}(\mathrm{g} / \mathrm{L})$ & 33,5 & 37,1 \\
$\mathrm{ART}_{\mathrm{c}}(\mathrm{g} / \mathrm{L})$ & 42,4 & 42,3 \\
$\operatorname{Biomassa}(\mathrm{g} / \mathrm{L})$ & 3,56 & 4,10 \\
\hline
\end{tabular}

$\mathrm{ART}_{\text {inicial }}$ (açúcar redutor total inicial $)=70,5 \mathrm{~g} / \mathrm{L}$ $\mathrm{AR}_{\text {inicial }}($ açúcar redutor inicial $)=56,8 \mathrm{~g} / \mathrm{L}$

$\mathrm{Na}$ fermentação descontínua desenvolvida em escala maior (3L), a produção de ácido lático em 48 horas de cultivo foi de $37,5 \mathrm{~g} / \mathrm{L}$, o que corresponde a $89 \%$ do valor teórico. Siebold et al. (1995) obtiveram 30g/L quando cultivaram L. delbrueckii em caldo MRS contendo glicose 3\%, através de fermentação descontínua em fermentador de 3L. Este valor corresponde a 99,4\% de produção teórica. Utilizandose L. casei subsp. rhamnosus, estes mesmos autores, verificaram $89,9 \%$ de produtividade nas mesmas condições, destacando a importância do 
microrganismo utilizado. Nestes experimentos, o valor de $\mathrm{pH}$ 6,0 foi mantido durante o processo fermentativo para evitar qualquer inibição da produção de ácido lático por queda de $\mathrm{pH}$.

Martínez-González et al. (1988) avaliaram a fermentação lática do $L$. delbrueckii em meio de melaço de cana-de-açúcar hidrolisado com ácido sulfúrico e calor, obtendo $66,81 \mathrm{~g} / \mathrm{L}$ de ácido lático em fermentador de $2 \mathrm{~L}$, contendo $95 \mathrm{~g} / \mathrm{L}$ de açúcares redutores totais no melaço. Nestas condições obtiveram uma eficiência de $96,4 \%$ e consumo de açúcares de 62,28g/L em 24 horas de cultivo. $\mathrm{O}$ pH foi mantido a 5,8; a agitação foi de 150 r.p.m. e temperatura de $40{ }^{\circ} \mathrm{C}$.

O consumo de açúcares redutores pelo $L$. curvatus em fermentador de $3 \mathrm{~L}$ foi de $65 \%$, portanto, menor do que o consumo obtido em frascos erlenmeyers de $20 \mathrm{~mL}$ que foi $92,5 \%$. Entretanto, os parâmetros cinéticos $\mathrm{Y}_{\mathrm{p} / \mathrm{s}}$ (eficiência de conversão de substrato) e $\mathrm{Y}_{\mathrm{p}}$ (produtividade volumétrica) foram maiores na fermentação de $3 \mathrm{~L}$, sendo $0,89 \mathrm{~g} / \mathrm{g}$ e $0,78 \mathrm{~g} /$ $\mathrm{L} / \mathrm{h}$ para $\mathrm{Y}_{\mathrm{p} / \mathrm{s}}$ e $\mathrm{Y}_{\mathrm{p}}$, respectivamente, quando comparados à fermentação em frascos de $20 \mathrm{~mL}$ $(0,87 \mathrm{~g} / \mathrm{g}$ e $0,63 \mathrm{~g} / \mathrm{L} / \mathrm{h})$.

Montelongo, Chassy e McCord (1993) avaliaram, através da fermentação descontínua, a produção de ácido láctico por L. salivarus, utilizando-se melaço de soja como substrato. O melaço de soja é um subproduto, obtido na preparação de proteína de soja, que contém a-galactosídeos. Esse substrato utilizado na concentração de $2 \%(\mathrm{~m} / \mathrm{v})$ sem suplementação produziu $4,2 \mathrm{~g} / \mathrm{L}$ de ácido lático correspondendo a $85 \%$ de produtividade em 36 horas de cultivo. Quando meio de melaço $2 \%(\mathrm{~m} / \mathrm{v})$ foi suplementado com extrato de levedura $0,5 \%(\mathrm{~m} / \mathrm{v})$, verificaram uma produção de ácido lático de $5,5 \mathrm{~g} / \mathrm{L}$ e um consumo de açúcar de $98 \%$, enquanto que em melaço sem suplementação o consumo de açúcar foi de $89 \%$. Os resultados têm demonstrado a necessidade de suplementação do melaço com fonte de nitrogênio como o extrato de levedura, para melhorar a produção de ácido lático pelas bactérias láticas.
Quanto à viabilidade celular os valores obtidos em 48 horas de cultivo foram de 1,32 x 109 ; $5 \times 10^{9}$; e $2,8 \times 10^{10} \mathrm{UFC} / \mathrm{mL}$, para fermentação de $20 \mathrm{~mL}$ em melaço de cana-de-açúcar suplementado, fermentação de 3L em melaço de cana-de-açúcar suplementado e em caldo MRS, respectivamente. Verificou-se uma maior produção de células de $L$. curvatus em meio de caldo MRS que é o meio sintético utilizado para bactérias láticas.

\section{Conclusões}

O melaço de cana-de-açúcar, previamente tratado com invertase, é uma alternativa economicamente viável para a obtenção de ácido lático.

O L. curvatus cultivado em meio de melaço suplementado com extrato de levedura e peptona apresentou uma boa produção de ácido lático (30,5 $\mathrm{g} / \mathrm{L}$ ) quando comparada à obtida em caldo MRS (32 $\mathrm{g} / \mathrm{L})$.

A fermentação lática descontínua, em fermentador de 3L,desenvolvida pelo L. curvatus em meio de melaço de cana-de-açúcar suplementado apresentou um pequeno aumento nos valores dos parâmetros de eficiência de conversão de substrato em produto, produtividade volumétrica e produtividade teórica em relação à fermentação descontínua em escala menor.

A viabilidade celular do L. curvatus cultivado em meio de melaço de cana-de-açúcar suplementado, em fermentador de $3 \mathrm{~L}$ e em escala menor, foi sempre maior que $1 \times 10^{9} \mathrm{UFC} / \mathrm{mL}$, ou seja, valor satisfatório quando comparado ao obtido em meio de MRS.

\section{Agradecimentos}

À CAPES e CPG-UEL pelo apoio financeiro.

\section{Referências}

BARROS, B. N.; SCARMINIO, I. S.; BRUNS, R. E. Como fazer experimentos: pesquisa e desenvolvimento na ciência e na indústria. Campinas: UNICAMP, 2001. 
BARUFFALDI, R. Produção de ácidos por microrganismos. In: LIMA, U. A.; AQUARONE, E.; BORZANI, W. Biotecnologia: tecnologia das fermentações. São Paulo: Edgard Blücher. 1975. v.1, cap.4, p.70-87.

BUCHTA, K. Latic acid. In: REHN, H. J.; REED, G. Biotechnology. Florida: Verlag Chemic, 1983. v.3, cap.3, p.409-417.

DEMIRCI, A.; POMETTO, A. L.; LEE, B.; HINZ, P. N. Media evaluation of lactic acid repeated-batch fermentation with Lactobacillus plantarum and Lactobacillus casei subsp. rhamnosus. Journal of Agricultural and Food Chemistry, Washington, v.46, n.11, p.4771-4774, nov.1998.

EVANGELISTA, R. L.; NIKOLOV, Z. L. Recovery and purification of lactic acid from fermentation broth by adsorption. Applied Biochemistry and Biotechnology, Totowa, v.57/58, p.471-480, 1996.

GOUVEIA, E. F. Produção de substância antifúngica por cultivo submerso de Bacillus spp. em melaço de canade-açúcar. 1995. Dissertação (Mestrado em Ciências de Alimentos) - Departamento de Tecnologia de Alimentos e Medicamentos, Universidade Estadual de Londrina, Londrina.

HO, K. G.; POMETTO, A. L.; HINZ, P. N.; DEMIRCI, A. Nutrient leaching and end product accumulation in plastic composite supports for L-(+)-lactic acid biofilm fermentation. Applied and Environmental Microbiology, Washington, v.63, n.7, p.2524-2532, 1997.

HUJANEM, M.; LINKO, Y. Y. Effect of temperature and various nitrogen sources on $\mathrm{L}(+)$ lactic acid production by Lactobacillus casei. Applied Microbiology and Biotechnology, Berlin, v.45, n.3, p.307-313, 1996.

JAGNOW, G.; DAWID, W. Biotecnología: introducción con experimentos modelo. Zaragoza: Acribia, 1991.

LIMA, U. A.; AQUARONE, E.; BORZANI, W. Biotecnologia: tecnologia das fermentações. São Paulo: Edgard Blücher, 1975. v.1

LITCHFIELD, J. H. Microbiological production of lactic acid. In: NEIDLEMAN, S. L.; LASKIN, A. Advances in Applied Microbiology. California: Academic Press, 1996. v.42, cap.2, p.45-95.

MARTÍNEZ-GONZÁLEZ, Y.; QUIROZ-CAMACHO, M. H.; LEDEZMA-PÉREZ, A. S.; JARAMILLO-CORONADO, J. C. Produccíon de ácido láctico a partir de melaza pretratada utilizando Lactobacillus delbrueckii. Revista Latino-americana de Microbiologia, México, v.30, n.2, p.209-214, 1988.
MONTELONGO, J. L.; CHASSY, B. M.; McCORD, J. D. Lactobacillus salivarus for conversion of soy molasses into lactic acid. Journal of Food Science, Chicago, v.58, n.4, p.863-866, 1993.

MORAES, I. O.; CAPALBO, D. M. F.; MORAES, R. O. Multiplicação de agentes de controle biológico. In: BETTIOL, W. Controle biológico de doenças de plantas. Brasília: EMBRAPA, 1991. p.253-272.

NELSON, N. A Photometric adaptation of the Somogyi method for determination of glucose. Biochemistry, Washington, v.153, p.375-380, 1944.

NEPOMUCENO, M. F. Cinética enzimática II: cinética enzimática da invertase. In: NEPOMUCENO, M. F. Bioquímica experimental. Piracicaba: UNIMEP, 1998. p.57-60.

OLIVEIRA, A. S. Desenvolvimento de Inoculante para Fermentação Lática de Silagens: utilização de resíduos agroindustriais. 1995. Tese (Doutorado em Ciências de Alimentos) - Departamento de Tecnologia de Alimentos e Medicamentos, Universidade Estadual de Londrina. Londrina.

SELMER-OLSEN, E.; SORHAUG, T. Comparative studies of the growth in whey supplemented with autolysate from brewery yeast biomass or commercial yeast of Lactobacillus plantarum extract. Milchwissenschaft, Munich, v.53, n.7, p.367-370, 1998.

SIEBOLD, M.; FRIELING, P. V.; JOPPIEN, R.; RINDFLEISCH, D.; SCHËGERL, K.; RÖPER, H.Comparison of the production of lactic acid by three different Lactobacilli and its recovery by extraction and electrodialysis. Process Biochemistry, Rickmansworth, v.30, n.1, p.81-95, 1995.

SILVA, D. J. Determinação do pH, da acidez titulável e do ácido lático da silagem. Análise de Alimentos: métodos químicos e biológicos. Viçosa: UFV, 1981. Cap.14,p.110-114.

SILVA, S. S.; MANCILHA, I. M. Aproveitamento de resíduos agroindustriais: ácido lático uma alternativa. Boletim da Sociedade Brasileira de Ciência e Tecnologia de Alimentos, Campinas, v.25, n.1, p.37-40, 1991.

SOMOGYI, M. A. A new reagent for determination of sugar. Journal of Biological Chemistry, Bethesda, v.160, p.61-68, 1945.

ZAYED, G.; WINTER, J. Batch and continuous production of lactic acid from salt whey using free and immobilized cultures of Lactobacilli. Applied Microbiology and Biotechnology, Berlin, v.44, p.362-366, 1995.

ZAYED, G.; ZAHRAN, A. S. Lactic acid production from salt whey using free and agar immobilized cells. Letters in Applied Microbiology, Oxford, v.12, p.241-243, 1991. 
